\title{
REACTIVATION POTENCY OF NEW GROUP OF ACETYLCHOLINESTERASE REACTIVATORS AND THEIR COMPARISON WITH CURRENTLY AVAILABLE OXIMES
}

\author{
Kamil Kuča ${ }^{1,2}$, Jan Pícha ${ }^{3}$, Daniel Jun ${ }^{1,2}$ \\ University of Defence in Brno, Faculty of Military Health Sciences in Hradec Králové, Czech Republic: Centre of \\ Advanced Studies ${ }^{1}$, Department of Toxicology2; Prague Institute of Chemical Technology, Prague, Czech Republic: \\ Department of Organic Chemistry ${ }^{3}$
}

\begin{abstract}
Summary: In this work, in vitro potency of novel serie of monoquaternary pyridinium oximes to reactivate cyclosarin-inhibited acetylcholinesterase (AChE) was tested. Currently available oximes (pralidoxime, obidoxime, trimedoxime, HI-6 and BI-6) were used as oximes for comparison. As resulted, none of tested new reactivators was able to reactivate AChE inhibited by cyclosarin. Also pralidoxime, obidoxime and trimedoxime did not reach good reactivation results. Only oximes HI-6 and BI-6 achieved sufficient reactivation potency. From obtained results, it can be deduced, that only reactivators with oxime group in position two are able to reactivate cyclosarin-inhibited AChE.
\end{abstract}

Key words: Oxime; Reactivator; Acetylcholinesterase; Cyclosarin; Nerve agent; In vitro

\section{Introduction}

Currently used antidotes against nerve agent intoxications consist of anticholinergics (atropine mainly) and acetylcholinesterase (AChE; EC 3.1.1.7) reactivators (pralidoxime, obidoxime and HI-6) (4). Unfortunately, abilities of these antidotes are limited. For example, soman inhibited $\mathrm{AChE}$ is after several minutes not treatable due to the aging (dealkylation) $(5,6)$. Also AChE inhibited by tabun and cyclosarin is difficult to reactivate due to the lone electron pair at the amide group (tabun) or presence of bulky cyclohexyl group (cyclosarin), respectively $(1,7)$ Currently the most promising AChE reactivator - oxime HI-6 - is not able to reactivate tabun or pesticide-inhibited AChE $(1,14)$.

Due to this fact, many laboratories throughout the world are interested in the synthesis of new AChE reactivators with better reactivation potency $(2,8,9-15)$. There were synthesized new reactivators differing in the number of quaternary pyridinium rings, in the length of the connection chain between pyridinium rings, presence of other heteroarenium rings, using of different functional groups or in the presence and position of oxime groups. There are also several works aimed to elucidate the relationship between structure of $\mathrm{AChE}$ reactivators and their biological activities $(3,10)$.

Unfortunately, till today, there was not synthesized one broad-spectrum AChE reactivator able to satisfactorily reactivate AChE inhibited by all kinds of nerve agents (broad spectrum reactivator) $(4,10)$. In 2005 , we have prepared new group of potential $\mathrm{AChE}$ reactivators with oxime groups in position four at the pyridinium rings. According to our former results, $\mathrm{pKa}$ of some of these reactivators were promising and comparable with currently available oximes (13).

In this work, we wanted to test if also reactivation potency of newly developed oxime is promising as their $\mathrm{pKa}$. For this purpose, in vitro reactivation potency of nine new potential AChE reactivators was tested. Their reactivation potency was compared with currently available oximes (pralidoxime, obidoxime, trimedoxime, HI-6 and BI-6). Cyclosarin was used as the appropriate member of the nerve agent family.

\section{Material and Methods}

All tested AChE reactivators were synthesized earlier at our department (13). Their purities were tested by $1 \mathrm{H}-$ NMR (Varian Gemini 300; $300 \mathrm{MHz}$ ) and TLC using DCAlufolien Cellulose F (Merck, Germany) and elution $\mathrm{BuOH}-\mathrm{CH}_{3} \mathrm{COOH}-\mathrm{H}_{2} \mathrm{O} 5: 1: 2$, detection by solution of Dragendorf's agent (solution containing $10 \mathrm{ml} \mathrm{CH}_{3} \mathrm{COOH}$, $50 \mathrm{ml} \mathrm{H}_{2} \mathrm{O}$ and $5 \mathrm{ml}$ of basic solution prepared by mixing of two fractions - fraction I.: $0.85 \mathrm{~g} \mathrm{Bi}\left(\mathrm{NO}_{3}\right)_{3}, 40 \mathrm{ml} \mathrm{H}_{2} \mathrm{O}$, $10 \mathrm{ml} \mathrm{CH} \mathrm{COOH}_{3} \mathrm{Craction} \mathrm{II} .: 8 \mathrm{~g} \mathrm{KI}, 20 \mathrm{ml} \mathrm{H}_{2} \mathrm{O}$ ). Nerve agent cyclosarin (O-cyclohexylmethylfluorophosphonate) was obtained from the Military Technical Institute (Brno, 
Czech Republic) and was of 95\% purity. All other chemicals used in this experiment were purchased from Fluka and Aldrich (Czech Republic) and used without further purification.

In vitro testing of reactivators involved a standard collection of experimental procedures. The whole method is in detail described in the work of Kuca and Cabal (10). Their efficacy was evaluated in $10 \%$ rat brain homogenate that was incubated with cyclosarin for 30 minutes and then, the tested oxime of appropriate concentration $\left(10^{-4}\right.$ and $\left.10^{-2} \mathrm{M}\right)$ was added for 10 minutes. Afterwards, the activity of brain AChE was determined using potentiostatic method with the use of automatic titrator RTS 822 (Radiometer, Den- mark). The data about initial rate of enzyme reaction with substrate were transformed to the percentage of increase in the activity of reactivated enzyme in the reaction mixture.

\section{Results and Discussion}

All results obtained are shown in Table 1. As it can be clearly seen, all newly developed reactivators were not able to reactivate cyclosarin-inhibited AChE. Also three oximes used for comparison were poor reactivators. Only two oximes (HI-6 and BI-6) were potent reactivators of cyclosarininhibited AChE. Moreover, these oximes seem to be very promising because of their sufficient reactivation potency

Tab. 1: Structures and reactivation activity of tested AChE reactivators.

\begin{tabular}{|c|c|c|c|c|c|c|c|c|c|}
\hline No & Name & Structures & $\begin{array}{c}\text { Reacti- } \\
\text { vation } \\
\text { potency } \\
{[\%]^{*}} \\
\end{array}$ & 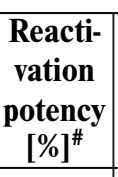 & No & Name & Structures & 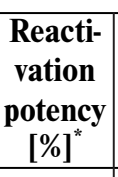 & 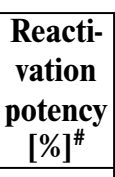 \\
\hline 1 & Pralidoxime & & 4 & 0 & 8 & K119 & & 0 & 0 \\
\hline 2 & Obidoxime & & 4 & 2 & 9 & K121 & & 0 & 0 \\
\hline 3 & Trimedoxime & & 0 & 0 & 10 & K122 & & 1 & 0 \\
\hline 4 & HI-6 & & 52 & 28 & 11 & K123 & & 0 & 0 \\
\hline 5 & BI-6 & & 57 & 60 & 12 & K124 & & 0 & 0 \\
\hline 6 & 4-РАM & & 0 & 0 & 13 & K125 & & 0 & 0 \\
\hline 7 & K120 & & 0 & 0 & 14 & K126 & & 0 & 0 \\
\hline
\end{tabular}

* concentration of tested reactivators $0.001 \mathrm{M}$; ${ }^{\#}$ concentration of tested reactivators $0.00001 \mathrm{M}$ 
at lower concentration $\left(10^{-5} \mathrm{M}\right)$. If both oximes are compared, BI- 6 seems to be the best reactivator tested in this work.

As described in introduction, searching for new broadspectrum reactivators still continues. Synthesis of many AChE reactivators of different chemical structures demonstrates this fact $(2,8,9-15)$. Unfortunately, till today, there exists no single reactivator able to satisfactory reactivate AChE inhibited by all kinds of nerve agents $(4,9)$.

According to our results, unfortunately, none of the newly developed reactivators was able to reactivate cyclosarininhibited AChE. From the oximes tested as compounds for comparison, only two oximes (HI-6 and BI-6) were potent reactivators of cyclosarin-inhibited AChE. Trimedoxime, obidoxime, pralidoxime and 4-PAM were poor reactivators of cyclosarin inhibited AChE. Obtained results confirm that bisquaternary oximes (BI-6 and HI-6) are more potent reactivators compared to monoquaternary ones (pralidoxime, 4-PAM, K119-K126) (9). Moreover, it is clear from the results that reactivators with oxime group at the position two are the most potent reactivators of cyclosarin-inhibited AChE. These results are in good agreement with our previous results $(9,11)$.

Main reason for the insufficient reactivation potency of novel reactivators seems to be the presence of the oxime group in position four, which is considered to be favourable in the case of tabun and pesticide inhibitions (1). Due to this fact, in former studies, the whole serie of new oximes should to be tested in this manner.

Thanks to our present knowledge of structural requirements of $\mathrm{AChE}$ reactivators, at this place, we could predict structure of probably the most promising AChE reactivators, which should be synthesized in future. This reactivator should be bisquaternary compound having in its structure two oxime groups both at separate pyridinium rings. Position of the oxime group should be two at the first pyridinium ring and four at the second pyridinium ring. Ideal length of the connection chain should be three or four membered.

\section{Conclusion}

Unfortunately, none from the newly developed monoquaternary pyridinium oximes was able to reactivate cyclosarin-inhibited AChE. As shown from the results, bisquaternary AChE reactivators seem to be more potent oximes compared to monoquaternary ones. However, also obidoxi- me and trimedoxime did not reach good reactivation results. Only oximes HI-6 and BI-6 achieved sufficient reactivation potency. From the results obtained, it can be conluded, that only bisquaternary reactivators with oxime group in position two are able to reactivate cyclosarin-inhibited AChE.

\section{Acknowledgement}

The authors are grateful to Mrs. M. Hrabinová and Mr. P. Stodůlka for their skilful technical assistance. This work was supported by Grant Agency of the Czech Republic (grant No. 203/01/1093) and Ministry of Defense of the Czech Republic, grant - "New method of prophylaxis, decontamination, diagnosis and therapy in the case of intoxication with nerve agents and sulfur mustard“.

\section{References}

1. Cabal J, Kuča K, Kassa J. Specification of the structure of oximes able to reactivate tabun inhibited acetylcholinesterase. Bas Clin Pharmacol Toxicol 2004; 95 : $81-6$

2. Chennamaneni SR, Vobalaboina V, Garlapati A. Quaternary salts of 4,3' and 4,4'bis-pyridinium monooximes: Synthesis and biological activity. Bioorg Med Chem Lett 2005; 15: 3076-80.

3. Gray AP. Design and structure-activity relationships of antidotes to organophosphorus anticholinesterase agents. Drug Met Rev 1984; 15: 557-9.

4. Kassa J. Review of oximes in the antidotal treatment of poisoning by organophosphorus nerve agents. J Toxicol Clin Toxicol 2002; 40: 803-16.

5. Kassa J, Bajgar J. Changes of acetylcholinesterase activity in various parts of brain following nontreated and treated soman poisoning in rats. Mol Chem Neuropathol 1998; 33: 175-84

6. Kassa J, Cabal J. A comparison of the efficacy of a new asymmetric bispyridinium oxime $\mathrm{BI}-6$ with currently available oximes and $\mathrm{H}$ oximes against soman by in vitro and in vivo methods. Toxicology 1999; 132: 111-8.

7. Kassa J, Cabal J. A comparison of the efficacy of acetylcholine reactivators against cyclohexyl methylphosphonofluoridate (GF agent) by in vitro and in vivo methods. Pharmacol Toxicol 1999; 84: 41-6.

8. Kim TH, Kuča K, Jun D, Jung YS. Design and synthesis of new bis-pyridinium oximes as cyclosarin-inhibited acetylcholinesterase reactivators. Bioorg Med Chem Lett 2005; 15: 2914-17.

9. Kuča K, Jun D, Musilek K. Structural requirements of acetylcholinesterase reactivators. Mini Rev Med Chem 2006; 6: 269-77.

10. Kuča K. Cabal J. Evaluation of newly synthesized reactivators of the brain cholinesterase inhibited by sarin-nerve agent. Toxicol Mech Meth 2005; 15: 247-52.

11. Kuča K, Patočka J. Reactivation of Cyclosarin-inhibited Rat Brain Acetylcholinesterase by Pyridinium-Oximes. J Enzyme Inhib Med Chem 2004; 19 : 39-43.

12. Pang YP, Kollmeyer TM, Hong F, Lee JC, Hammond PI, Haugabouk SP, Brimijoin S. Rational design of alkylene-linked bis-pyridiniumaldoximes as improved acetylcholinesterase reactivators. Chem Biol 2003; 10: 491-502.

13. Pícha J, Kuča K, Kivala M, Kohout M, Cabal J, Liška F. New group of monoquaternary reactivators of the acetylcholinesterase inhibited by nerve agents. J Enzyme Inhib Med Chem 2005; 20: 233-7.

14. Worek F, Kirchner T, Bäcker M, Szinicz L. Reactivation by various oximes of human erythrocyte acetylcholinesterase inhibited by different organophosphorus compounds Arch Toxicol 1996; 70: 497-503.

15. Yang GY, Yoon JH, Seong CM, Park NS, Jung YS. Synthesis of Bis-pyridinium oxime antidotes using bis(methylsulfonoxymethyl) ether for organophosphate nerve agents. Bull Korean Chem Soc 2003; 24: 1368-70.

Submitted July 2006. Accepted November 2006.

\section{Corresponding author:}

ing. Kamil Kuča, Ph.D., Department of Toxicology, Faculty of Military Health Sciences, University of Defence, Trebešská 1575, 50001 Hradec Králové, Czech Republic, e-mail: kucakam@pmfhk.cz, kucakam@seznam.cz 